\title{
ist \\ El individuo como pluralidad: de la citología a la filosofía nietzscheana de los años 1880
}

Irene Audisio

\begin{abstract}
茴
RESUMEN

Durante los años 1880, Nietzsche propone una idea original de individuo en tanto pluralidad como un modo de superación del difundido nihilismo con respecto a la unidad. Sus escritos, tanto editados como inéditos, presentan una crítica aguda de la concepción heredada de unidad anímica y cultural acorde con la crisis de identidad que vive Europa en la segunda mitad del siglo xix. Nuestro objetivo es mostrar un hilo que va desde la biología celular hasta la filosofía de Nietzsche. Consideramos cómo la biología celular, especialmente con Rudolph Virchow, inauguró la crítica de la noción de Individuum desde el plano orgánico. Eso constituyó un motivo fuerte en la psicología de los franceses Hippolyte Taine y Theódule Ribot, quienes transpusieron el problema al ámbito anímico y de la psicopatología. Ambos concluyeron con un fuerte cuestionamiento sobre la unidad y simplicidad del yo. Eso generó un profundo interés en la filosofía de Nietzsche que en repetidas ocasiones se refiere al Individuum como una multiplicidad de células. Finalmente, profundizaremos en el registro nietzscheano acerca del Individuum, ya que constituye uno de los costados del pensamiento sobre el Übermensch, que Nietzsche imagina inspirado en los grandes hombres del Renacimiento, como posible superación del nihilismo.
\end{abstract}

Palabras-clave $\bullet$ Nietzsche. Virchow. Citología. Individuo. Taine. Ribot.

\section{INTRODUGCIÓN}

Las reflexiones de Nietzsche sobre la pluralidad del individuo, atentas a las ideas de psicólogos franceses como Hippolyte Taine y Theódule Ribot, marcan un anclaje del yo en el cuerpo. Sin comprometerse con un reduccionismo biológico, el filósofo alemán muestra un nuevo enfoque que desmantela la ficción del sujeto. Postula, en su lugar, una unidad entendida como resultado - siempre provisorio y en riesgo - de la pluralidad dinámica de fuerzas. La teoría celular es clave en esta trayectoria del cuestionamiento del estatuto del individuo. Se alcanzará a ver hasta qué punto la citología propicia reflexiones inauditas acerca del problema, cuando consideremos las transposiciones y los intercambios semánticos que se fueron llevando a cabo entre biología, psicología 
y filosofía, en relación a la definición de individuo. Nos enfocaremos en el impacto de la teoría elaborada por Virchow en la psicología de Taine, y en su posterior asimilación crítica por parte de Nietzsche para la elaboración de su propio panorama filosófico con respecto al individuo.

Taine (1870) es el primero que pone en duda el supuesto carácter unitario y compacto de nuestra individualidad psíquica. Anteriormente, en el campo de la biología, Virchow (1858) había puesto en cuestión la individualidad de los organismos afirmando que estos eran compuestos de auténticos individuos, es decir, las células. Taine toma impulso en esas investigaciones citológicas y biológicas, en general, para poner en cuestión el concepto de individualidad remisible, en todos sus elementos, al sustrato fisiológico. En los últimos decenios del siglo, un discípulo suyo, Ribot, va más allá, dividiendo la personalidad, en el campo de la psicopatología, en una multiplicidad colonial. Taine y Ribot contribuyeron de manera decisiva a la inversión de concepciones difundidas y de tradiciones religiosas y filosóficas muy arraigadas. Sus investigaciones, que articulan los datos biológicos con reflexiones psicológicas, hacen que el yo, la conciencia, deje de ser considerado una unidad monolítica, una sustancia simple e inmortal, para convertirse en un compuesto inestable. El yo de los individuos normales no es el único del que estos están provistos, sino que es el que se instituye en hegemónico al tomar el control de una coalición en frágil equilibrio. Ribot posee un rasgo adicional significativo para nuestro campo de estudio. Es quien introdujo en Francia las obras psicológicas de Herbert Spencer y la filosofía de Arthur Schopenhauer. ${ }^{1}$

Nietzsche se mantuvo al tanto de las teorías de Taine y de su discípulo, ya sea leyendo directamente sus obras, como a través de la Revue Philosophique de la France et de l'Étranger ${ }^{2}$ - órgano de difusión de las discusiones psicológicas y filosóficas de fines del siglo xIx, no solo de Francia sino también de Inglaterra y Alemania -, e incluso estableció un contacto epistolar con Taine.

1 Tradujo y prologó, junto a Espinas, los Principes de psychologie (1892) de Spencer. Además, se presentan numerosas referencias a su psicología, por ejemplo, en La psychologie anglaise contemporaine (1881). Escribió también La philosophie de Schopenhauer (1874).

2 La Revue Philosophique de la France et de l'Étranger fue fundada por Ribot en 1876 . Fue la primera revista francesa de filosofía del siglo xIx que no funcionó como órgano de una escuela, sino abierta al diálogo entre las corrientes filosóficas. En la misma, Taine y Ribot publicaban adelantos de sus obras. Nietzsche fue un atento lector de la misma. 
El individuo GOMO PLURALIDAD...

\section{EL “yo” DEL FILÓSOFo, EL “NOSOTROS” DEL Biólogo:}

\section{LA BIOLOGÍA GELULAR Y EL REPLANTEO DE LA DEFINIGIÓN DE “INDIVIDUO”}

El ámbito en el que primero se pone en cuestión el concepto de individuo y de unidad es el de la biología celular. Uno de los campos científicos de investigación con los que Nietzsche se contacta, a través de Albert Lange (1866). El tratamiento biológico del tema instala la analogía entre el microcosmos individual y el macrocosmos social, y constituye una de las fuentes de inspiración de las investigaciones de los autores estudiados. Al mismo tiempo, la recepción de estas investigaciones en la filosofía y en la psicología, que al comienzo tienen como protagonistas a Schleiden (1838) y Schwann (1839), muestra cuán poderoso se vuelve el modelo del saber biológico para el resto de los campos de indagación. Siguiendo el impulso del positivismo inglés, Taine y Ribot adjudicarán a la ciencia biológica y a su método un valor normativo modélico para el abordaje de temas psicológicos. La citología es el saber en el que ambos psicólogos franceses enmarcan su crítica del concepto unitario de individuo psicológico y de las facultades. Asimismo, Nietzsche se nutre en ambas, biología y psicología, para desarrollar su propia revisión del concepto de individuo, con una profundidad y agudeza que superan los planteos trazados hasta el momento.

En las investigaciones biológicas se manifiesta una creciente relativización del concepto de "individuo". Durante toda esta etapa, y hasta fines del siglo xix, se tiende a considerar al organismo pluricelular como un agregado de unidades vitales inferiores. En el marco de tal perspectiva, las investigaciones biológicas mismas afrontan la cuestión de la individualidad en el mundo orgánico y, al mismo tiempo, definen y circunscriben nuevos campos de interés para reflexiones filosóficas más amplias.

Jakob Schleiden (1838) es quien genera el momento crucial de la historia de la moderna teoría celular, negando que el concepto de individuo encuentre algún empleo en el mundo vegetal, dado que cualquier planta se presenta como "un agregado de seres individuales, plenamente individualizados y en sí independientes: las células" (p. 137, 168 ss.). Theodor Schwann (1839, p. 199) amplía al mundo animal y rectifica estas conclusiones al descubrir una estructura celular en los tejidos animales. La célula comienza a considerarse la unidad elemental de cualquier ser viviente, y se inicia una nueva disciplina dedicada a la indagación de su morfología y leyes generales de desarrollo.

Tanto para Schleiden como para Schwann las células tienen en sí estatuto de individuos. Y, según el último, "las células son, en sentido estricto, los organismos", mientras que la planta y el animal solo son "un agregado de estos organismos ordenado según determinadas leyes” (Schwann, 1839, p. 225). El organismo global constituye 
una multiplicidad existente en virtud de la acción recíproca de las partes elementales, es solo la resultante de sus interacciones. Tal imagen será profundizada en el posterior desarrollo de la teoría celular, en las obras de Rudolf Virchow, quien en la biología de la década del 1850 difunde la tendencia de superar el concepto de individuo disolviéndolo en un complejo abigarrado de nexos y relaciones. Virchow (1858) propone considerar cualquier organismo como "una suma de unidades vitales, cada una de las cuales manifiesta todas las características de la vida" (p. 12). La intuición de esta "suma" encierra una gran complejidad. Abandona la idea de orden jerárquico y, por ello, propone que el carácter y la unidad de la vida no se pueden encontrar en un punto determinado de una organización superior, por ejemplo en el cerebro, sino en la disposición, en la organización (Einrichtung) de los elementos individuales periféricos y en su capacidad autónoma de regularse. Se trata así de la asociación o contraposición de innumerables procesos locales, de intercambios de carácter periférico, no regulados, en principio, por ninguna instancia central. Como consecuencia, en base a esa doctrina celular, originada en estudios de estados patológicos, el organismo animal se presenta como co-presencia de desfases, contigüidades entre ritmos y modos de desarrollo totalmente independientes entre sí. En cualquier tejido "en la cadena de trabajo de las células, prevalece una cierta independencia de los miembros, y esta independencia se evidencia en el hecho de que cada célula individual sufre una transformación específica, sin que a esto se ligue necesariamente el destino de las células limítrofes" (Virchow, 1858, p. 14). Virchow cambia la idea del organismo como unidad sustancial por la de

una especie de disposición social (...) en la que una cantidad de existencias individuales son mutuamente dependientes, pero de modo tal que cada elemento tiene su propia acción particular, y que cada uno, aun cuando recibe el estímulo a la actividad propia desde otra parte, sin embargo ejecuta por sí mismo su propio deber (Virchow, 1858, p. 12-3).

Al mismo tiempo que Spencer retoma la teoría de Schleiden y Schwann, Virchow, en Alemania, reformula la teoría en base a una explicación diferente de la citogénesis, a partir del descubrimiento de la división celular. Según esta, la individualidad de la célula no es el resultado de un proceso de diferenciación, sino algo dado desde el inicio, preexistente a la interacción funcional con otras células, en virtud de su existencia en el seno de la "confederación" del organismo. En Virchow la célula se afirma como "individuo" contrapuesto a "átomo". Nos detendremos brevemente en esa diferenciación, ya que consideramos que se vincula, mediada por la recepción de Taine y Ribot, con el planteo nietzscheano sobre el Individuum y su crítica a la última forma del atomismo, 
el "atomismo anímico" (Nietzsche, 1983, p. 34). ${ }^{3}$ Según Virchow, si bien ambos términos significan lo indivisible y la unidad, el individuo es tangible, sensible. Los individuos son unidades en las cuales se pueden distinguir partes, no son partículas últimas como es el caso de los átomos. El individuo es una mancomunidad (commonwealth) unificada, en la que todas las partes - que pueden ser diferentes y tener diversos alcances - trabajan juntas para un fin común o actúan de acuerdo a un plan definido. El átomo no es cambiante sino permanente, mientras el individuo es cambiante y transitorio. Los átomos pueden entrar en las más complicadas combinaciones y agruparse con otros átomos, pero pueden retirarse en cualquier momento con todas sus propiedades intactas. Si el individuo tuviera que someterse completamente a la unión con otros, necesariamente renunciaría a su individualidad. Por ello, sus relaciones más intrínsecas mantienen un reconocible rasgo de exterioridad. El individuo puede asimilar, pero no puede permitir ser asimilado. Todo individuo, aunque pertenezca a un grupo más grande, mantiene sus características particulares. Virchow acentúa la relevancia de la libertad y la autodeterminación para la definición del individuo. Por lo tanto, la individualidad es un rasgo exclusivo del mundo orgánico. En el mundo inorgánico de los cristales no hay individualidad. Además, en su máximo desarrollo, el fenómeno total de la individualidad conlleva el sello de la unidad. Aunque las partes fueran multitudinarias y complicadas, todas son partes de una comunidad en la que cada una está relacionada con las otras y requiere de las otras, y no tiene sentido fuera del todo. No es fácil captar esta unidad porque la unidad del individuo descansa en la mancomunidad de sus partes. A partir de esta distinción entre átomo e individuo, Virchow aborda la pregunta por el organismo ¿Qué es un organismo? Una sociedad de células vivas, un diminuto Estado bien ordenado que abarca en su unidad una multiplicidad.

Virchow afirma que cada uno de nosotros representa en sí mismo un tipo de sociedad, tal como las plantas y animales. Entonces ¿de dónde proviene nuestra percepción de nosotros mismos como unidades simples? La misma se genera por nuestro deseo, nuestras necesidades estéticas y el conocimiento filosófico, que se ven contradichos por la intuición de que no somos más que una asociación de partes, y que como individuos orgánicos no tenemos existencia excepto como una comunidad. Establece la primacía teórica de la ciencia natural sobre el juicio estético que, como tal, nunca puede prescribir leyes a la ciencia natural. Por otra parte, el conocimiento filosófico debe basarse en la investigación científica para la comprensión de la naturaleza. Contra las nociones de la Naturphilosophie, cita a Goethe (1997).

3 Para las citas de Nietzsche referimos a la edición de Colli y Montinari (1994). En el caso de contar con obras traducidas al castellano en versiones reconocidas y basadas en la edición de las obras completas arriba mencionada, hemos referido la edición traducida. Esto ocurre con La genealogía de la moral (2000), Más allá del bien y del mal (1983) y Humano, demasiado humano (1996). 
Toda cosa viva no es simple sino múltiple, aunque nos parezcan individuos son sin embargo una asociación de seres vivientes autosuficientes que, aunque parecidos en idea o plan, pueden ser en sus manifestaciones idénticos o similares, diferentes o disímiles. (...) La criatura menos desarrollada es en la que más parecidas son sus partes y estas se parecen al todo. La más altamente desarrollada llega a ser aquella en la que sus partes son más disímiles. Cuanto más parecidas sean sus partes menos están subordinadas. La subordinación de partes señala una criatura más altamente desarrollada (Virchow, 1858, p. 115-7).

A partir de esto, y teniendo en cuenta casos de botánica y de animales, Virchow se plantea cuestiones tales como:

¿Cuál es el individuo? ¿Cuál es el órgano? ¿Los mismos órganos son individuos? ¿El todo es solo una colección de individuos? ¿Una familia, una colonia, o incluso, como dice Vogt, un falansterio? (...) ¿Deberemos acaso aceptar verdaderamente estos animales-plantas como términos de parangón para nuestra individualidad, compacta y totalmente unitaria? ¿Debemos confrontar nuestra naturaleza con criaturas tan inferiores? (Virchow, 1862, p. 66-7).

Respondiendo esas cuestiones, lejos de establecer una jerarquía de niveles de individualidad, Virchow restringe el uso estricto de ese término para el nivel básico celular. En el mundo orgánico, el concepto de individuo o bien debe dejar de utilizarse, o bien debe ser vinculado a la célula. Virchow es partidario de la segunda opción, pues, a ella conduciría una visión realista desprejuiciada de la naturaleza, es decir, una visión superadora de los impulsos artísticos y filosóficos; una visión, podríamos decir, científica. De ese modo se asegura una concepción unificada de la vida a través del campo total de plantas y organismos animales. Virchow (1858, p. 115-7) transforma relaciones y jerarquías ordenadas unívocamente en modalidades mucho más complejas de interacción, en juegos de intercambios entre innumerables "epicentros"; nada, en absoluto, que se pueda atribuir a "un único punto central (...) a partir del cual sean guiadas de modo reconocible las actividades del cuerpo" (Virchow, 1858, p. 255-6). Ni siquiera el sistema nervioso jugará un rol unificador central ya que - afirma Virchow si bien

hemos encontrado, en el aparato nervioso, pequeños órganos celulares determinantes que sirven de puntos intermedios del movimiento, pero no encontramos en absoluto un ganglio del cual brote, en última instancia, el movimiento entero, sino solo innumerables ganglios de este tipo (...). Por esto las sensaciones se 
El individuo GOMO PLURALIDAD...

agrupan en ganglios determinados, pero tampoco aquí encontramos un ganglio, que pueda ser definido como centro de todas las sensaciones, sino, nuevamente, muchísimos centros muy diminutos (Virchow, 1858, p. 256-7).

A partir de ello, el autor concluye que en la actividad que surge del sistema nervioso no podemos reconocer una unidad. Las aseveraciones de la teoría celular de Virchow son afines a las investigaciones de Steenstrup, Siebold, Leuckart, Braun que consideran como dividua más que como individua los organismos de la botánica y, seguidamente, los organismos animales tal como los sifonóforos. La presunta unidad es producto de nuestra conciencia. "En ningún lugar, al menos hasta hoy, se ha podido mostrar una unidad anatómica o fisiológica" (Virchow, 1858, p. 256-7). De esta manera se opera una descentralización del organismo, que queda definido como un compuesto de superposiciones e intersecciones de innumerables centros vitales relativamente autónomos.

Ese mismo desplazamiento de una instancia considerada hasta ese momento central ejercerán los psicólogos franceses. Apoyados en una fisiología del sistema nervioso como la que describe Virchow, ponen en tela de juicio el concepto de alma unitario, simple e inmortal de los espiritualistas y eclécticos. La teoría celular, en efecto, mostraría que no se puede dudar de que a través de los fenómenos de nuestro yo, al interpretar los procesos orgánicos, somos continuamente inducidos al engaño.

Nosotros, que nos percibimos a nosotros mismos como una cosa simple y unitaria (...) partimos siempre de la idea de que toda cosa debe resultar determinada por este mismo carácter unitario (...). Toda la actual fisiología de las plantas se apoya sobre la indagación de la actividad celular, y si todavía hoy se muestra reticente a introducir el mismo principio también en la economía animal, esto no depende, creo yo, de ninguna otra dificultad fuera de la de no poder superar la indecisión de orden estético y moral (Virchow, 1858, p. 257).

En ese sentido, Virchow afirma que "el yo del filósofo es solo una consecuencia del "nosotros' del biólogo" (1862, p. 72-3). Es necesario, por lo tanto, liberarse del axioma de la unidad para entender la relación entre las partes constituyentes del organismo biológico. Virchow es quien saca todas las consecuencias de la teoría celular para reestructurar profundamente el concepto de individualidad biológica. La individualidad en sentido estricto es en Virchow adscripta a las células, las únicas pasibles de definirse como Einzel-Individuen, a diferencia de los Sammel-Individuen (cf. Virchow, 1862, p. $7^{3}$ ), individuos colectivos como es el caso de los organismos. La vida de las células desde el comienzo es originariamente autónoma de la del organismo, y no está condi- 
cionada por una instancia central. Si bien existe una conexión entre las células que constituyen el organismo, no habría que suponer "una unidad anatómica y fisiológica" que, según Virchow, "no se ha podido mostrar hasta ahora en ningún lugar" (Virchow, 1862, p. 15-6). El autor admite que existen múltiples focos de actividad vital sin que eso comprometa necesariamente la unidad del organismo (cf. Virchow, 1858). Mantiene la noción de una unidad que no tiene un spiritus rector, admite un Estado libre conformado por entidades con igualdad de derechos, pero no idénticas. En última instancia, son las diversas células las que dotan de vida a la "unidad comunitaria" del organismo.

Debemos notar que los aportes virchowianos no están aislados, sino que expresan una dirección de investigación muy difundida en la época a partir de los estudios de biología celular. En las décadas siguientes, el evolucionismo, en la versión de Ernst Haeckel, acentúa una nueva propiedad de la naturaleza orgánica, su plasticidad. El concepto de individuo sufre así tal deflación que, en el ámbito de la botánica, la evolución de la vida es considerada, más que un sucederse de individualidades bien definidas, la acción de fuerzas plásticas. La capacidad de adaptación de los organismos no depende del grado de unidad, es decir, del nivel de centralización, sino de la relativa independencia de múltiples "centros vitales", de la ausencia de una cohesión demasiado rígida.

En resumen, en esos años, el concepto de individuo sufre dos relativizaciones. Primero, el organismo tiende a descomponerse en una pluralidad de centros vitales, elementales y relativamente autónomos; y, segundo, la identidad morfológica del individuo (y de la especie) se resuelve en la variabilidad de las formas.

La aplicación de la teoría celular a la patología conduce a Virchow a negar que la relación entre las partes del organismo sea pensable en términos de armonía. En los años cincuenta, propone la metáfora del Zellenstaat. Este término sugiere que el microcosmos celular también puede estudiarse como un campo de relaciones jerárquicas, conflictos locales, latentes o explícitos, equilibrios precarios y sistemas complejos de autonomía recíproca. De esta idea surge otro terreno de analogías fecundas entre el microcosmos de las interacciones celulares y el macrocosmos de las relaciones éticas que constituye un vector sugestivo para el tratamiento que Nietzsche dará posteriormente al tema del individuo. En lugar de una unidad como instancia centralizadora, Virchow piensa en una actividad reguladora comunitaria y policéntrica colocada en diversos Mittelpunkte, ${ }^{4}$ centros organizadores del organismo no subsumidos bajo ninguna unidad previa. Si resulta una unidad, lo es en tanto organización de la multiplicidad.

4. En consonancia con esa idea y con respecto a la individualidad, Nietzsche propone centros de gravedad cambiantes (fragmento póstumo, 34 [123], de abril-junio 1885, SW, 11, p. 461). El término es utilizado ya por Ribot. Sobre ese particular, véase Audisio, 2012. 
En sintonía con las ya presentadas investigaciones en biología, entre las décadas de 1850 y 1860 se establece una conexión entre la nueva concepción de la individualidad orgánica y la teoría neurofisiológica que conduce la discusión al ámbito de la individualidad psíquica. El texto del neurofisiólogo Pflüger (1853), 5 en el que estudia "las funciones sensoriales de la médula espinal", discutido por Lotze, Fichte, von Hartmann, Lange, Wundt y Dilthey, ${ }^{6}$ pone en cuestión la individualidad psíquica. Contra el "dogma" de los fisiólogos, consagrado por la escuela mülleriana, de que "el alma - o el sensorium - representa un todo unitario, indivisible", Pflüger sostiene la divisibilidad de la conciencia (cf. 1853, p. 3o). No solo las formas animales "inferiores", sino los vertebrados mismos, deben tener filamentos nerviosos no centralizados rígidamente y, por lo tanto, una pluralidad de centros de consciencia independientes entre sí, dado que, por ejemplo, movimientos en gran medida voluntarios, capaces de alguna regulación y rectificación, se observan en ranas decapitadas, las cuales ofrecen al observador la "prueba de la actividad de la médula espinal en términos ya sea de sensaciones, ya sea de voluntad" (Pflüger, 1853, p. 115). La idea de una inteligencia plural, localizada en la médula espinal, disuelve la individualidad psíquica. Lleva a pensar que lo psíquico no goza de derechos especiales o del privilegio de un orden jerárquico (la exclusividad del cerebro como órgano de la conciencia), dado que también en los vertebrados se trataría de una composición de funciones que, del mismo modo que cualquier proceso natural, resultan difusos y descomponibles (Orsucci, 1992, p. 98-9). Lange (1866, p. 438-9) dedicó una página, que Nietzsche luego refundió parcialmente en el Tercer Tratado, §15 de La genealogía de la moral (2000, p. 162-5), a los experimentos de Pflüger sobre el significado psíquico de los centros nerviosos de la médula espinal.

Asimismo las tesis de la biología celular impactaron profundamente, en especial vía Spencer, en las teorías de Taine sobre la pluralidad del sujeto psicológico con las que Nietzsche también tuvo familiaridad.

\section{De la Biología a la PSigología:}

\section{la Pluralidad del individuo Psicológico en De l'intelligence de TAine}

Siguiendo los desarrollos de las teorías citológicas, Taine toma como modelo para su psicología una perspectiva fisiológica según la cual el entramado constitutivo del ser vivo se constituye de células de diversas clases, capaces de desarrollo espontáneo y modificables por el concurso o antagonismo de células vecinas. Basándose en estas

5 Sobre este autor, desde el abordaje de los temas del presente trabajo, cf. Orsucci, 1992; Gauchet, 1994, p. 73-89. 6 Lotze, Lange y Wundt son tenidos en cuenta por Ribot en su La Psychologie Allemande Contemporaine, y Wundt, en particular, es uno de los autores que publican en la Revue editada por Ribot. 
teorías, Taine afirma que, desde el punto de vista de la psicología, lo que configura el ser que piensa son las sensaciones y las imágenes de diversas clases, dotadas de ciertas tendencias y modificadas en su desarrollo por el concurso o antagonismo de otras imágenes. A partir del desenmascaramiento de las ilusiones forjadas por el lenguaje, Taine toma la imagen del polípero para la descripción del organismo y de la mente; un polípero de células mutuamente dependientes y un polípero de imágenes mutuamente dependientes, respectivamente $(1870,1$, p. 124). En ambos casos la unidad no es más que una armonía y un efecto, se trata de un producto del equilibrio de la actividad mental, de un balance entre tendencias alucinantes y rectificaciones constantes.

De un modo original, en el plano psicológico, Taine afirma que cada imagen está provista de una fuerza automática y tiende espontáneamente a cierto estado que tiene el carácter de una alucinación, pero es contrarrestada por la contradicción de una sensación de otra imagen o grupo de imágenes. El equilibrio de la trama mental se produce así por el conjunto de detenciones y represiones mutuas, de impulsos recíprocos. Ese balance tiene como efecto el estado de vigilia razonable. El yo en sí mismo no es más que un compuesto de fuerzas y potencias. No tiene otros elementos más que los hechos sucesivos - las sensaciones - que forman una trama continua. No se trata de una unidad simple como suponían los espiritualistas.

El presupuesto epistemológico de la dependencia de la vida psicológica de la fisiología lleva a Taine a transponer las conclusiones de la fisiología a la psicología (cf. Taine, ${ }_{18} 86$ ). En base a experimentos de vivisección de una Mantis religiosa, de pólipos y de anélidos, que retoma de Vulpian (1866), el francés concluye que cada uno de los segmentos es un animal completo estando el animal total formado de varios animales elementales colocados unos a continuación de otros (cf. Taine, 187o, 1, p. 34.3). Al separarlos, cada uno es un centro independiente de acciones reflejas, coordinadas y adaptadas a un fin. La única diferencia con los mamíferos es el grado de independencia de los segmentos. Tal como había hecho Virchow en el nivel celular, Taine utiliza figuras políticas. Compara la república de los centros nerviosos de los animales inferiores, todos iguales y casi independientes, con la monarquía de centros desiguales en desarrollo de los animales superiores, estrechamente unidos y sometidos a un centro principal. La centralidad y organización no suprimen la pluralidad constitutiva y, a medida que se avanza en la escala, esa se distancia del estado de suma hasta llegar al de individuo.Taine descompone la conciencia en miríadas de sensaciones, imágenes e ideas. Muestra la naturaleza de esta frágil e inconsistente coalición de un agregado cambiante y siempre en tensión entre integración y desintegración, cuya capa superficial constituye la conciencia $(1870,1$, p. 3). La unidad del sujeto psicológico designada con la palabra "yo" se basa en la idea adquirida por la asociación de un grupo de elementos coordenados cuya combinación normal no es más que un éxito, no se termina ni se 
renueva sino por la derrota continua de fuerzas contrarias desintegradoras. Así el espíritu avanza a través de delirios y locuras amenazantes, casi siempre impunemente, manteniendo el fino hilo de la conciencia saludable gracias al papel abreviador de la memoria, del hábito y de la repetición. Taine considera la razón como "una adquisición tardía y un compuesto frágil" cuya salud "no es más que un logro frecuente y un bello azar" en los espíritus superiores (1986, p. 145, 178-9). El yo es el fruto frágil de una organización superficial emergente de un trasfondo primitivo de impulsos feroces y latentes que amenazan constantemente con irrumpir y provocar la locura individual o social.

Por todo lo dicho, en Taine, el yo tiene un carácter virtual como un "punto matemático" (1870, 2, p. 201), pero dependiente del buen funcionamiento de una base corporal múltiple y dinámica, un agregado cuyos elementos colaboran entre sí, en un flujo intermitente y discontinuo.

\section{El alma como "estrugtura social”}

Desde 1880 hasta 1887 aproximadamente - más intensamente en los fragmentos de 1884 - comienza a sobresalir, en los escritos de Nietzsche, el tratamiento del problema acerca de la pluralidad y unidad biológico-social del alma humana. Tanto en Aurora como en La ciencia jovial, ${ }^{7}$ Nietzsche se concentra en un enfoque corporizado de la naturaleza humana. En 1886, con la edición de Más allá del bien y del mal, refina su crítica de la unidad del yo. En esta obra se condensan nuevas hipótesis alternativas al respecto: "(...) conceptos tales como 'alma mortal', 'alma como pluralidad del sujeto' y 'alma como estructura social (Gesellschaftsbau) de los instintos y afectos' (...)" (Nietzsche, 1983, p. 33). Allí mismo, Nietzsche refiere expresamente la imagen social al cuerpo: "nuestro cuerpo, en efecto, no es más que una estructura social de muchas almas", una colectividad de "sub-almas" o "sub-voluntades" (Nietzsche, 1983, p. 411). Atribuye a la ilusoria unidad psicológica no solo un carácter múltiple en lugar de simple, sino también una dinámica socio-política que regula las relaciones de dominio entre las partes. Nos detendremos aquí en esa hipótesis política del alma, a través de la cual se hace patente la intención de Nietzsche de no dejar librado el concepto de alma a una multiplicidad indiferenciada. La pretendida simplicidad del yo es puesta en movimiento según el modelo de la estructura social, ámbito privilegiado para el juego de relaciones de dominio y de constante lucha y asimetría.

A pesar de que, en general, autores como Thiele (1990) o Casares (1996) adjudican la idea de tratar al individuo como una comunidad a la adopción de la imagen 
platónica tripartita del alma como un Estado, diferimos de esa referencia, ya que podría rastrearse dicha figura de modo más directo a través de la sugerente lectura que Nietzsche realiza de la obra de biólogos como Virchow, quien transpone imágenes políticas al estudio en citología, como ya hemos presentado. A través de estas lecturas, se rastrea su propuesta del individuo (Individuum) como una pluralidad de vivientes relacionados al modo de una sociedad, entendida esta como un hecho natural y no como un contrato de las partes. Nietzsche aplica las mismas metáforas del registro sociopolítico tanto al alma microcósmica (cf. Nietzsche, 1996, p. 176) del individuo humano como al alma macrocósmica del pueblo alemán o de la Europa a los cuales se refiere también como individuos (cf. Nietzsche, 1983, p. 196-9, 214-7).

La consideración nietzscheana de la multiplicidad dinámica como constitutiva del cuerpo se expresa en el §19 de Más allá del bien y del mal (Nietzsche, 1983, p. 39-411), indicando también que la identidad personal no está presupuesta en la base del edificio; por el contrario, es el efecto de las relaciones sociales entre las múltiples fuerzas que interactúan en el cuerpo. Por eso el autor agrega "l'effet c'est moi" (el efecto soy yo). La denominada, más exactamente, "unitariedad" (Einartigkeit) del alma, en lugar de estar presupuesta, es el resultado de la lucha. Es, por lo tanto, un proceso siempre en devenir.

Toda unidad es solo como organización y coordinación una unidad, al igual que una comunidad humana es una unidad. O sea lo contrario de la anarquía atomística; por tanto una estructura de dominio, que significa unidad, pero no lo es (Nietzsche, fragmento póstumo 2[87] otoño 1885-otoño 1886, SW, 12, p. 104).

Vemos así cómo Nietzsche cristaliza la intuición de que la complejidad del yo es dejada de lado por la expresión lingüística simplificante "yo". Por otra parte, se hace patente el esfuerzo de Nietzsche por abandonar esta simplificación, sin disolver la unidad que caracteriza la individualidad, y su búsqueda de redefinir la unidad del sujeto psicológico.

\section{LA GONQUISTA DE LA UNITARIEDAD GOMO LUCHA DE FUERZAS}

Nietzsche reconoce en la metáfora social del alma una jerarquía de órganos e instintos, y una diferencia entre las funciones superiores e inferiores, que se explican en términos de dependencia de quien obedece con respecto a quien manda (cf. fragmento póstumo 25 [411] primavera 1884, SW, 11, p. 119). Esa necesidad de postular un orden entre las partes del organismo en lucha había sido vislumbrada por Wilhelm Roux (1881), 
pero acotada a términos fisiológicos y con un carácter mecanicista, él se había referido a una "autorregulación" (Selbstregulation). ${ }^{\mathbf{8}}$ Nietzsche produce una nueva semántica de los conceptos mecanicistas de Roux, y propone pensarlos como expresiones de la capacidad de dominio sobre la comunidad que constituye los organismos mismos. En 1884, Nietzsche refina su hipótesis contrastando la mirada mecanicista de la fisiología con su intuición de la espontaneidad inherente de las partes del organismo. El proceso de autorregulación que según los fisiólogos está determinado por los estímulos tróficos y trópicos debe ser concebido, según Nietzsche, como un proceso activo de luchas internas desatadas por la propia fuerza espontánea de cada parte que busca descargarse. En sus notas de 1884, luego de haber leído a Roux, repasa las tesis del fisiólogo y apunta a superar el último resto estático de la imagen de la multiplicidad orgánica. El filósofo introduce un modelo dinámico de fuerzas espontáneas que no responde a estímulos del medio sino a un impulso de dominio. Nietzsche encuentra presupuesta en la autorregulación de la multiplicidad anímica la "capacidad de dominio sobre una comunidad" (fragmento póstumo, 26[272] y [273], verano-otoño 1884, SW, 11, p. 221), alejándose de descripciones tanto mecanicistas como teleológicas.

En el proceso orgánico

(1) hipercompensación - expresión falsa y teñida teleológicamente

(2) autorregulación, la capacidad de dominio sobre una comunidad, es decir, que el desarrollo posterior de los organismos no está unido a la nutrición, sino al mandar y a la capacidad de dominar: la nutrición es solo un resultado (Nietzsche, fragmento póstumo, 26 [272], de verano-otoño de 1884, SW, 11, p. 221).

Taine también había llegado a una conclusión semejante a partir de su consideración del individuo fisiológico y psicológico como una estructura compuesta de partes autónomas ordenadas jerárquicamente según su desarrollo. "El hombre total se presenta como una jerarquía de centros de sensación y de impulso, cada uno con su iniciativa, sus funciones y su dominio" (1870, v. 1, p. 8). En estos autores, las jerarquías son derivadas de las luchas observables ya en los más simples procesos orgánicos. Pero en Nietzsche, a diferencia de lo sostenido por el darwinismo de Haeckel, Hartmann, Oken, la evolución y la diferenciación de los organismos no dependen de determinadas propiedades químicas o de factores ambientales, sino de un complejo juego de estructuras, de fuerzas y de tensiones organizadas (cf. Orsucci, 1992, cap. 5). Nietzsche continúa madurando la intuición de que en cada uno de los procesos orgáni-

8 Para presentar la relación entre la obra de Roux y la de Nietzsche nosotros seguiremos de cerca la exposición del tema en el excelentísimo artículo de Müller-Lauter (1992). 
cos, el ser viviente - no refiriéndose exclusivamente al organismo total, sino también a sus partes - no se limita a adaptarse, sino que busca descargar su fuerza. La nutrición es un ejemplo.

Nutrición primitiva: el protoplasma alarga sus seudópodos para encontrar algo que se le oponga - no por hambre, sino por voluntad de poder. La voluntad de poder puede manifestarse solo en contra de las resistencias; busca aquello que se le contrapone - esta es la tendencia originaria del protoplasma (fragmento póstumo, $9\left[15^{1}\right]$ otoño de 1887, SW, 12, p. 424).

Nietzsche afirma, a diferencia de los planteos de los científicos, que en la descarga de poder de una "voluntad" orgánica tal como el protoplasma, considerado ya "una multiplicidad de seres en lucha entre sí" (fragmento póstumo, 35 [59], de mayojulio 1885 , SW, 11, p. $5^{3} 7$ ), lo que esta busca es la ampliación de su poder, volverse más fuerte. Eso puede hacerlo solamente en la lucha con algo que se le resiste. De este modo, Nietzsche traduce la lucha interna como un acaecer mecánico-causal a una lucha de fuerzas espontáneas, es decir, de voluntades. Él reformula todo tipo de evento como una "superación de un poder sobre otro poder", como voluntad de poder (Nietzsche, fragmento póstumo, 14[81], de primavera 1888, SW, 13, p. 260; 1983, p. 61-2). Una voluntad que busca otra que se le resista tenderá a su superación, apropiándose de ella y asimilándola. El elemento superado puede, entonces, ser tomado al servicio de aquél que lo asimiló sin ser anulado. El resultado es una jerarquía que en las estructuras orgánicas complejas comportan los procesos de "autorregulación", presentando una lucha continua entre las instancias que dan órdenes y las que obedecen. Esta jerarquía fisiológica es traducida por Nietzsche en una jerarquía de estados anímicos (1983, p. 158-9).

En Taine también se presentaba una jerarquía fisiológica que se correspondía con una psíquica. Sin embargo, en él, el cuadro es mucho más estático. La jerarquía no es resultante de una lucha de fuerzas dinámicas, sino una estructura mental, consecuencia de una organización de los hechos físicos dados. A diferencia del francés, Nietzsche afirma que el ser humano es "una pluralidad de 'voluntades de poder': cada una con una pluralidad de medios expresivos y formas" (Nietzsche, fragmento póstumo, 1 [58], de otoño de 1885-primavera de 1886, SW, 12, p. 25). Una multiplicidad de fuerzas, es decir, de instintos y afectos, que buscan algo que se les resista para poder descargar la fuerza que traen consigo; que están en lucha entre sí, y cuyos mecanismos de acción se producen a través del mandar y del obedecer.

El mapa que el filósofo arma de esa interacción de los impulsos incorpora tal complejidad que incluso considera la acción de una fuerza sobre otra de manera bila- 
teral. El hecho de mandar a otros hace que los que obedecen se modifiquen en base al mandato. El estímulo proveniente de aquellos que mandan hace que los que obedecen cumplan por sí mismos un cambio en sí mismos. El elemento asimilado puede ejercitar la función que le ha sido prescrita solamente si la asume espontáneamente. De este modo, Nietzsche remarca la espontaneidad proveniente desde el interior de los elementos superados. Intuición inédita hasta el momento.

Si bien el concepto de jerarquía es controversial, revisando su génesis en la filosofía nietzscheana, podremos distinguir ciertos matices que encierra tal idea. Cuando Nietzsche (cf. SW, 3, p. 118, 53o) comienza a formular su concepto de la globalidad funcional orgánica como una jerarquía, lo hace de una manera bastante simple. A través de una lucha continua, unas fuerzas más poderosas dominan a otras que, a su vez, también someten a otras más débiles. La conservación de las luchas entre las fuerzas se constituye en la condición vital de la totalidad. La obediencia es concebida aún solo como constricción. No se tiene presente la recepción diferenciada de los estímulos por parte de los subyugados. Se trata de un proceso unidireccional. Sin embargo, como ha detectado Müller-Lauter (1992, p. 190 ss.), a partir de fragmentos posteriores hay un cambio explícito acerca de esta noción. Nietzsche sigue apegado a las definiciones de Roux al sostener que en la autoafirmación de las entidades individuales se encuentra, al mismo tiempo, la afirmación de la globalidad. Sin embargo, tiene una visión más diferenciada de la relación de dependencia del elemento que obedece de aquél que manda. Para la ejecución de una orden en el organismo, es necesario un gran número de individuos que deben comprender la orden y también ver en ella su finalidad específica (cf. Nietzsche, fragmento póstumo, 27 [19], de verano-otoño 1884, SW, 11, p. 279).

Nietzsche reconoce una relativa independencia del elemento que obedece, que ejerce también resistencia y oposición. La globalidad del cuerpo humano se presenta como "una enorme unión de seres vivientes, cada uno dependiente y obediente y, sin embargo, en cierto sentido, a su vez, comandante y agente con voluntad propia" (Nietzsche, fragmento póstumo, 37 [4] ], de junio-julio 1885, SW, 11, p. 576). Se trata de una magnífica vinculación de la vida más múltiple, un orden y una coordinación de las actividades superiores e inferiores, según la cual los que rigen dependen, a su vez, de los gobernados. En el hombre, los roles entre quienes mandan y quienes obedecen deben intercambiarse provisoriamente (cf. Nietzsche, fragmento póstumo, 34.[123], de abril-junio 1885, SW, 11, p. 461). Efectivamente, la hipótesis nietzscheana sobre la pluralidad anímica-corporal postula "centros de gravedad" móviles. Es decir, si bien Nietzsche sugiere una multiplicidad ordenada, no se trata de una estructura estática. Aspecto que muchas veces no ha sido tenido en cuenta en las recepciones de sus obras. 
El ser humano como pluralidad: la fisiología presenta solo la alusión a una asombrosa circulación entre esta pluralidad, y subordinación y orden de las partes de una totalidad. Pero sería falso deducir de un Estado la necesidad de una monarquía absoluta (la unidad del sujeto) (Nietzsche, fragmento póstumo, 27[8], de verano-otoño 1884, SW, 11, p. 276).

El ser humano es una multiplicidad de fuerzas que están en una jerarquía, de tal modo que existe la que ordena, pero que también la que ordena debe trabajar por todas las que obedecen, eso sirve para su conservación (...). Todos estos seres vivientes deberían ser de especie análoga, de lo contrario, no podrían servir y obedecer a uno: los que sirven deberían, en algún sentido, ser también los que obedecen, y en casos más precisos debe cambiar transitoriamente el rol entre ellos, y el que en general manda, debe obedecer (...). El centro de gravedad central es algo variable; el continuo generar de las células, etc. da un continuo cambio del número de estos seres. Y con la suma no se consigue nada (Nietzsche, fragmento póstumo, 34 [123], de abril-junio 1885, SW, 11, p. 461).

A la base de esa multiplicidad en lucha, Nietzsche ubica explícitamente la pluralidad celular. Esa transposición de la dinámica celular al resto de los registros teóricos constituye el lugar donde se inicia la puesta en cuestión del individuo, un ámbito de problematización axial en la filosofía de Nietzsche. En un fragmento, el filósofo sugiere como base de la pluralidad del sujeto entendida como relaciones de comando-transformación, es decir, en términos de voluntad, la existencia de una aristocracia de células.

¿Una especie de aristocracia de células, sobre la que descansa la dominación? ¿Ciertamente una aristocracia de pares que entre sí están habituados a gobernar y que entienden de mandar? Mis hipótesis: el sujeto como pluralidad (...). La única fuerza que hay es del mismo tipo que la de la voluntad: un comandar a otros sujetos, que a partir de allí se transforman (Nietzsche, fragmento póstumo, $40[42]$, de agosto-septiembre de 1885, SW, 11, p. 650).

Se debe reconocer en la idea nietzscheana de aristocracia y de jerarquía la afirmación de los elementos superados que no son anulados. Es decir, las fuerzas vencidas no dejan de ser fuerzas activas. En ese universo anímico dinámico, cuyo eje es móvil y cambiante, el lugar que ocupen los elementos es el resultado de una lucha constante entre sí. Nietzsche no atribuye a las partes un papel estático, sino que imagina una lucha entre voluntades a partir de la espontaneidad en la acción que surge de cada una. El autor supone una autorregulación que equilibra la unidad y, de este modo, garantiza la salud. De otro modo, opina Nietzsche, si gobernaran todas al mismo tiempo, se vol- 
vería nocivo. La unidad psíquica se desintegraría en una anarquía de impulsos que terminaría por disolver la voluntad y la capacidad de actuar; se precipitaría en una descomposición de las partes. Esta idea de Nietzsche está claramente en consonancia con las proposiciones de Ribot, en su libro sobre las enfermedades de la voluntad, cuando analiza las causas de las debilidades de esta. Ribot había afirmado que la anarquía de impulsos, una multiplicidad indiferenciada de fuerzas, desintegra la voluntad y no logra cristalizar en una acción determinada (cf. 1883, p. 77). Como la voluntad constituye el hilo que da unidad al yo, la disolución de esta produce la pérdida del carácter y así de la unidad psicológica. Tanto en Nietzsche como en Ribot, el peligro de la disolución está siempre latente y sigue una marcha regresiva de lo más voluntario, de lo más complejo a lo menos voluntario, al automatismo. Sin embargo, a diferencia de Nietzsche, Ribot se queda apegado aún al plano fisiológico y a cierto determinismo del ambiente propio del modelo del positivismo y funcionalismo de Spencer.

Nietzsche propone pensar una unidad que asuma en sí la multiplicidad. La imagina como una dinámica flexible en constante modificación, asimilación y superación. Utiliza la imagen del proceso de división celular:

La esfera de un sujeto es constantemente creciente o menguante - el punto central del sistema se modifica constantemente -; en el caso en que no puede organizar la masa de la cual se ha apropiado se divide en dos. Por otro lado, puede transformar un sujeto más débil, sin destruirlo, en su funcionario y formar con él, hasta cierto grado, una nueva unidad; ninguna "substancia", sino más bien algo que en sí tiende al fortalecimiento, y que solo indirectamente se quiere "conservar" (se quiere superar) (Nietzsche, fragmento póstumo, 9[98], de otoño de 1887, SW, 12, p. 391).

Teniendo en cuenta teorías como la de Roux y la de Ribot, Nietzsche toma como punto de partida los procesos selectivos que se dan en la lucha interna del organismo. Pero superando las teorías de estos autores, considera las partes como voluntad de poder, afirmando que su dinámica no puede ser determinada desde el exterior, ni de antemano. Los organismos están constituidos por una sucesión interna de procesos de avasallamiento, de resistencias utilizadas para contrarrestarlos, de metamorfosis intentadas con una finalidad activa de defensa y de reacción, así como de los resultados de contra-acciones afortunadas.

El énfasis puesto por Nietzsche en esa dinámica se opone al socio-darwinismo de Spencer, que coloca en primer plano la adaptación. Esta es caracterizada como una "actividad de segundo grado", "una mera reactividad", que conlleva una fuerte pasividad del organismo frente al determinismo del medio. 
(...) se ha definido la vida misma como una adaptación interna, cada vez más apropiada, a circunstancias externas (Herbert Spencer). Pero con ello se desconoce la esencia de la vida, su voluntad de poder; con ello se pasa por alto la supremacía que poseen las fuerzas espontáneas, agresivas, invasoras, creadoras de nuevas interpretaciones, de nuevas direcciones y formas, (...) con ello se niega en el organismo mismo el papel dominador de los supremos funcionarios, en los que la voluntad de vida aparece activa y conformadora (Nietzsche, 2000, p. 102).

Nietzsche subraya la acción de la fuerza activa configuradora (formschaffende Kraft) desde el interior, de este modo, supera también el planteo funcionalista spenceriano asumido por Taine y Ribot y previene, asimismo, contra la afirmación del instinto de autoconservación como el principal instinto de un organismo.

Querer conservarse a sí mismo es la expresión de una situación de emergencia, una limitación del instinto verdaderamente fundamental de la vida que se dirige hacia la ampliación del poder, y que a través de esta voluntad muy a menudo cuestiona y sacrifica la autoconservación (SW, 3, p. 585).

Algo vivo quiere, antes que nada, dar libre curso a su fuerza - la vida misma es voluntad de poder -: la autoconservación es tan solo una de las consecuencias indirectas y más frecuentes de esto (Nietzsche, 1983, p. 34).

El influjo de las "circunstancias externas" ha sido sobrevalorado por D[arwin] hasta lo absurdo; lo esencial en el proceso vital es precisamente una enorme fuerza configuradora que da forma desde su interior, la cual utiliza en su provecho, explota, las “circunstancias externas" (Nietzsche, fragmento póstumo, ๆ [25], de fines de 1886, primavera de 1887, SW, 12, p. 3०4).

Tal como lo muestran numerosas anotaciones de Nietzsche, él considera que a partir de una tendencia activa, la autoconservación, la autorregulación y la capacidad de conservarse en la existencia de los organismos se convierten en fenómenos secundarios. La conservación no es más que una consecuencia de las descargas vitales de fuerza (Nietzsche, fragmento póstumo, 26[277], de verano-otoño de 1884, SW, 11, p. 222); "[La] nutrición [es] solo una consecuencia de la insaciable apropiación, de la voluntad de poder" (Nietzsche, fragmento póstumo, 2[76], de otoño 1885-otoño 1886, SW, 12, p. 96).

En base a estas confrontaciones puede comprenderse mejor la hipótesis nietzscheana del cuerpo como campo de lucha entre voluntades de poder. Efectivamente, traduce tanto los procesos psíquicos como los orgánicos a voluntad de poder en un intento por superar la dicotomía psíquico/fisiológico y el determinismo del medio. 
El individuo GOMO PLURALIDAD...

La vida misma es esencialmente apropiación, ofensa, avasallamiento de lo que es extraño, más débil, opresión, dureza, imposición de formas propias, anexión y al menos, en el caso más suave, explotación (...). La vida es cabalmente voluntad de poder (...), la "explotación" (...) forma parte de la esencia de lo vivo, como función orgánica fundamental (Nietzsche, 1983, p. 222).

De esta manera, el filósofo se distancia del planteo pasivo del organismo (entendido este como una unidad que solo cambia como resultado de las reacciones a las imposiciones del medio con el único fin de la supervivencia). Esta prerrogativa había sido asumida por el funcionalismo inglés que se extendió tanto en Alemania (vía Haeckel, principalmente) como en Francia (vía Taine, Ribot y Espinas). Entre las fuerzas que tejen el entramado dinámico del yo, hay una voluntad de dominio. Una tendencia unificadora a ir de la pluralidad a la simplicidad. En virtud de esta fuerza, se constituye en Individuum aquél capaz de situar a cuanto forme parte de su entera actividad consciente e inconsciente en una dimensión en la que ninguno de sus elementos sea privilegiado unilateralmente, ni tampoco sobrevalorado en relación con todos los ingredientes que forman parte de su efectiva, compleja y cambiante existencia histórica. "Grandeza debe llamarse precisamente el poder ser tan múltiple como entero, tan amplio como pleno" (Nietzsche, 1983, p. 156). El hombre más íntegro es aquél que no se dispersa, no se disuelve ni se descompone en su pluralidad constitutiva, sino que tiene la fuerza suficiente para darse a sí mismo una dirección desde sí mismo. Ese hombre sabe utilizar su fuerza, no para crear una obra, sino para tratarse a sí mismo como su obra (cf. SW, 3, p. 318), en el orden y selección dentro del torrente de impulsos. Aquí consideramos que Nietzsche juega con los diversos niveles del discurso transponiendo su intuición sobre la unidad orgánica a la unidad psicológica y a la construcción de la individualidad ética también.

Ante la multiplicidad constitutiva, Nietzsche piensa en la necesidad del primado de un aspecto dominante que organice. Adopta de Taine el concepto "faculté maitresse" o "instinto dominante" (dominierender Instinkt). Identifica la voluntad con esa fuerza dominadora. De este modo, su concepto de voluntad tiene en cuenta los estudios biológicos y psicopatológicos - aunque no se limita a adoptar acríticamente nociones de esos campos - y se opone claramente a la propuesta por Schopenhauer. En clave ribotiana (1883) Nietzsche considera que Schopenhauer ha malentendido la voluntad igualándola al deseo. Esa perspectiva constituiría un síntoma del cansancio o debilidad de la voluntad, ya que los deseos se constituyen en los amos y como tales son estos los que asignan a la voluntad su dirección y medida (SW, 12, p. 435). La posición de Schopenhauer es identificada como decadente, ya que expresa el agotamiento de la potencia vital en lugar de la fuerza plasmadora. 
A pesar de no ser compartida por todos los intérpretes, seguiremos aquí la línea de investigación de Campioni que avala la afirmación de que Nietzsche se apropia de la noción de voluntad de Ribot para transponerla a su crítica filosófica de la voluntad como facultad. ${ }^{9}$ A través de Ribot, reconduce la fuente de la voluntad a las operaciones biológicas que se cumplen en la intimidad de los tejidos, "en este sentido es lícito decir que ella es nosotros mismos" (Campioni, 2004, p. 61). La voluntad emerge de la lucha de fuerzas dada en el campo de los tejidos, de los órganos y del cuerpo en su totalidad. Con esto queremos remarcar que no hay un hiato cualitativo entre la lucha de las partes del organismo y la voluntad. La voluntad, tal como a Ribot, le aparece como "la coronación, el último término de una evolución, el resultado de un gran número de tendencias disciplinadas siguiendo un orden jerárquico" (Ribot, 1883, p. 74); el resultado de una conquista posible gracias a un cierto arte, a la educación, a la experiencia; una fuerza de coordinación que, como tal, expresa salud y vitalidad. Esto no significa que Nietzsche haya quedado preso del reduccionismo biológico propio de las líneas positivistas y spencerianas de la época. Su mirada filosófica transpone analógicamente estos conceptos al campo ético y político de la configuración del futuro europeo. Identifica entrecruzamientos entre registros orgánicos y procesos sociales y culturales, en base a los cuales proyecta la configuración de una sensibilidad de un tipo humano, un Individuum, capaz de superar la crisis que ha llevado a la disolución de la unidad en una multiplicidad, o al endurecimiento de una unidad que niega toda multiplicidad. Estas reflexiones cristalizan en el concepto articulador de la pars construens de la filosofía nietzscheana que es el de voluntad de poder. Concepto filosófico que incorpora la idea de una fuerza configuradora del organismo que cohesiona la multiplicidad de impulsos hasta lograr, en casos excepcionales, la construcción del Individuum.

Para Nietzsche, el Renacimiento es un reservorio de ejemplos de esos individuos capaces de contener la multiplicidad de fuerzas constitutivas. Siguiendo las exposiciones de Taine sobre el particular, ${ }^{10}$ el hombre del Renacimiento es apreciado

9 Al referirnos a la relación existente entre la filosofía nietzscheana y las lecturas científicas de la época como apropiación, es imprescindible tener presente la rica significación del término alemán “Auseinandersetzung”, que excluye una forma pasiva de mera receptividad y asimilación y supone, en su lugar, a un lector activo, que pondera los materiales seleccionando, tomando y rechazando, transformando lo dado en un proceso netamente dinámico. 10 Voyage en Italia y la Philosophie de l'art de Taine son ambos textos en los que Nietzsche encontró un esbozo de conjunto del Renacimiento que comparte. En el verano de 1878 , Nietzsche lee la traducción alemana de Histoire de la littérature anglaise de Taine y a través de este lee a Stendhal, a quien caracteriza, tal como lo habían hecho Taine y Bourget, como "hombre superior". Taine, en su ensayo sobre Stendhal, consolida y generaliza las expresiones de "hombre superior" y "espíritu superior". Las toma de Balzac y las aplica a Stendhal para expresar que es inaccesible a la masa, que "ama la soledad y escribe para no ser leído", que "inventa su conducta y ofende a la multitud gregaria que no sabe más que imitar" (Taine, 1909, p. 223, 229-30, 232). Es notable la congruencia con la terminología y la posición de Nietzsche, incluso el mismo término "moutonnière" (gregario) es usado por el filósofo alemán. 
por Nietzsche como tipo humano fuerte, en el sentido de síntesis de una pluralidad de fuerzas en movimiento y como apertura en las formas sociales y culturales: "no se subordina a valores trascendentes y rígidos, sino que ve en los valores instrumentos pragmáticos de la construcción de sí y del Estado - "obra de arte"” (Campioni, 2004, p. 172). En una comparación que realiza el filósofo entre Miguel Ángel, Rafael y Leonardo da Vinci, en la que es evidente la influencia de Stendhal y de Taine, se perfila Leonardo como el ejemplo del individuo "tan múltiple como entero, tan amplio como pleno" (Nietzsche, 1983, p. 156). Nietzsche reconoce en él la fuerza y movilidad necesarias para mantenerse en un sistema inacabado de perspectivas libres y abiertas, diferentes de las que se requieren para mantenerse en un mundo "dogmático" (fragmento póstumo 34 [25], 1885, SW, 11, p. 429). Taine se interesó por el Renacimiento (1858). Lo define como una época plena de fuerza y audacia inventiva. Hace referencia a las sanas "bestias de presa" renacentistas que muestran la plena afirmación de la potencialidad humana en contra del sentido de impotencia y de décadence del cristianismo medieval. El Renacimiento significa un retorno a los valores paganos de Grecia, enaltecimiento de la realidad del cuerpo y de la afirmación inmoralista de sus fuerzas, en contra de la enfermedad y las contradicciones del espíritu medieval. ${ }^{11}$ Nietzsche asume la valoración taineana del Renacimiento y ve en la figura de Napoleón a "uno de los más grandes continuadores del Renacimiento" (SW, 3, p. 6o9). Reconoce que el corso despliega esa faculté maîtresse, esa fuerza plástica configuradora, que puede dar algún orden al caos de las fuerzas que constituyen la realidad tanto interna como externa, cuya conceptualización Taine había desarrollado de modo central en sus obras.

En Ribot (1883), hay una apreciación similar en algunos aspectos. La suma de las tendencias coordinadas, desde el nivel del automatismo hasta las pasiones y las decisiones, constituyen el individuo. La coordinación más perfecta de estos componentes de la vida psíquica es la de las "voluntades superiores", de los "grandes activos" (cuyos ejemplos son César, Miguel Ángel o San Vicente de Paula) que gozan de "unidad, estabilidad y potencia".

El concepto nietzscheano de Individuum, esta unidad que supone en sí la pluralidad como base, es una de las ideas clave hacia la que se dirigen las reflexiones nietzscheanas maduras. Este concepto está intrínsecamente relacionado con la idea de voluntad de poder e integrado en la imagen del Übermensch. Sucintamente, Übermensch representa a aquel hombre capaz de superar la parcialidad de toda pers-

11 Renacimiento es en Nietzsche sinónimo de esa imagen geográfica de la claridad, vitalidad y energía del Sur siempre en contraste con el Norte. Sobre Italia, Nietzsche retoma motivos de Stendhal por intermedio de Taine. Tal es la frase: "La planta hombre nace allí más robusta que en cualquier otra parte", presente en el parágrafo 44 de Más allá del bien y del mal (fragmento póstumo, 27 [4, ], [59], de verano otoño de 1884, SW, 11, p. 285, 289; 34. [74], [14,6], [176], de abril-junio de 1885 , SW, 11, p. 443, 469, 478). 
pectiva vital, sin negarla sino incorporándola en una forma plena. Aquel que posee la fuerza de asimilar a sí mismo toda la realidad, a través de la afirmación (cf. Campioni, 2004, p.216). En este sentido, el Übermensch imaginado por Nietzsche, lejos de ser considerado un sujeto fundante, un alma inmortal o una unidad simple, parece mejor una batalla y una conquista constante.

\section{De la Biología a la Filosofía: DERROTEROS DE LA GRISIS DE LA UNIDAD DEL INDIVIDUO}

En conclusión, si bien, por una parte, el concepto de Individuum se vincula muy fuertemente con los grandes hombres del Renacimiento, por otra parte, la biología celular, especialmente con Virchow, inauguró la crítica de la noción de Individuum desde el plano orgánico y esto constituyó un motivo fuerte en la psicología de Taine y Ribot, en especial en su cuestionamiento sobre la unidad y simplicidad del yo. La biología celular debe ser considerada como una de las fuentes de sus reflexiones críticas sobre la multiplicidad de la unidad anímica y del individuo en general. Considerar estas fuentes permite valorar las reflexiones nietzscheanas sobre la multiplicidad fundante del individuo de un modo mucho más arraigado en un marco naturalista ${ }^{\mathbf{2}}$ que lo habitualmente presentado. Esta perspectiva naturalizada, creemos, echa una luz única sobre los planteos acerca de tópicos tales como "voluntad de poder" y Übermensch, centrales en el corpus nietzscheano.

Hemos mostrado sintéticamente el recorrido que Nietzsche realiza partiendo de la asimilación de las líneas biológicas y psicológicas y cómo, desde un registro filosófico de mucho mayor alcance, resignifica esos aportes para conceptualizar la multiplicidad constitutiva del Individuum. Su mirada filosófica transpone la cuestión al plano de su percepción de la crisis cultural que estaba viviendo Europa y el individuo europeo. En ese registro diverso al de las ciencias, incardina el problema en el pathos nihilista de fines del siglo xıx. El nihilismo trae aparejado el debilitamiento de los lazos que mantenían cohesionados internamente los impulsos que conforman la vida de los individuos. Se trata de la muerte de los antiguos órdenes que presuponían una individualidad humana compacta y unitaria, firmemente articulada en torno al "alma atomon". En efecto, la tradición occidental había sido edificada sobre la creencia en el alma en-

12 El término "naturalista" no refiere aquí a un naturalismo "cientificista". Este último ha sido claramente rechazado por Nietzsche (2000, p. 194-8) como una expresión más de ascetismo. Identificamos su naturalismo con una pauta más que con contenidos. Una dirección que guía una pretensión de rastrear la genealogía de ciertas sensibilidades y tipos humanos en un plano "mundano" desdivinizado y post-metafísico sin apelar a instancias explicativas subyacentes o trascendentes al mundo de la vida, la naturaleza y la historia (cf. Schacht, 2011). 
tendida filosóficamente como "substancia", substrato sobre el que fluyen constantemente las experiencias cambiantes, como entidad individual, inmaterial, simple e indivisible, y por esto incorruptible.

Una vez negada en el plano teórico su substancialidad, el fundamento estable del yo y la unidad de sus flujos de conciencia se vuelven inestables y precarios. A partir de esto, en el siglo XIx, las indagaciones sobre el yo se vuelven investigaciones en las que los datos científicos adquieren una notable articulación en la convergencia de diversos saberes (sobre todo citológicos, médicos y psicopatológicos) y la autonomía crítica de la perspectiva filosófica. El yo, el alma y la conciencia dejan de ser en su horizonte una unidad monolítica, un átomo simple e inmortal, para convertirse en un compuesto inestable, un archipiélago de "islas de conciencia", como lo describió Taine.

El desplazamiento de la base del yo, desde la conciencia al fondo de impulsos inconscientes corporales, revela la propia e intrínseca fragilidad y el hecho de que el yo está expuesto al peligro siempre inminente de la disgregación. Esto lo hace patente Ribot en su interés por las patologías mentales, y Nietzsche lo radicaliza incorporándolo como condición constitutiva del "yo plural", de la estructura social anímica. La psicología ya no parte del supuesto de la unidad y continuidad del yo, sino que, en su lugar, asigna a cada "unitariedad" (Einartigkeit) anímica una pluralidad originaria de polos de conciencia, que conviven bajo el dominio provisional de un yo hegemónico que no es el único. Su inestable "gobierno" se mantiene precariamente, con la amenaza nunca abolida de su debilitamiento y declinación capaz de desembocar en la disolución de la coalición de los yoes, con la consiguiente escisión de la conciencia y la multiplicación de las personalidades en las diversas formas de locura copiosamente estudiadas por la nueva psicología francesa.

El modelo explicativo que postula una dinámica entre polos de personalidades plurales como constituyente de la psiquis corresponde al debilitamiento de las constricciones sociales que requerían un individuo monolítico y anclado en papeles rígidamente asignados. En este contexto "conciencia", "yo" y "individuo" no constituyen núcleos meta-históricos dotados de una ontología fija, sino constructos interpretativos o modelos para hacer frente a la pérdida de sustancialidad del alma en vistas de posibles alternativas.

Nietzsche aspira a una unidad compatible con la pluralidad. Esa unidad será planteada como el efecto de la lucha de la multiplicidad en devenir de los instintos y afectos. Los individuos que sean suficientemente fuertes como para incorporar el espectro móvil de su propia esencia, sin desintegrarse, se constituirán en Individua. El concepto de "yo plural" alberga en su seno la multiplicidad en devenir y, por ello mismo, plantea a los protagonistas de esta gran crisis la tarea de convertirse en el experimento de sí mismos, en su propia obra de arte. Esta tarea está basada en el ejercicio de la propia 
fuerza configuradora que puede generar unidades dinámicas y cambiantes sin aplastar la multiplicidad de impulsos, ni desintegrarse en esa pluralidad. Dicha fuerza se traduce en voluntad de poder que posibilita el surgimiento de los Individua, tanto a nivel subjetivo como a nivel cultural, individuos colectivos capaces de generar unidades dinámicas a partir de la lucha constitutiva de diversas fuerzas.A

Irene Audisio

Centro de Investigaciones “María Saleme de Burnichón”,

Facultad de Filosofía y Humanidades, Universidad Nacional de Córdoba, Argentina. irene.audisio@gmail.com

Individual as plurality: from cytology to Nietzschean philosophy in the years 1880

\begin{abstract}
Among possible ways that Nietzsche can take to deal with Nihilism and its challenges, he proposes an original idea of plural individual. His papers both published and unpublished, present a sharp critique of the inherited view of psychic and cultural unit. It was in line with the identity's crisis faced by Europe along the second half of the nineteenth century. Our goal is to show a thread that goes from cell biology to Nietzsche's philosophy. We see how cell biology, precisely through Rudolph Virchow, inaugurated the critique of the notion of organic Individuum from the organic field. It became a strong subject in the psychology of Hippolyte Taine and Theódule Ribot. They transposed the issue to the field of mind and psychopathology. Both concluded in a strong challenge on the self's unity and simplicity. This generated a deep concern in Nietzsche's philosophy. He repeatedly refers to Individuum as a multiplicity of cells. Finally, we will go in deep into the Nietzschean consideration about Individuum because this topic means one important aspect of the concept of Übermensch that Nietzsche imagines inspired by the great men of the Renaissance as a promising way out of Nihilism.
\end{abstract}

KeYwords • Nietzsche. Virchow. Cytology. Individual. Taine. Ribot.

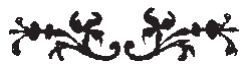


El individuo Gomo PLURALidAd...

\section{REFERENGIAS BIBLIOGRÁFIGAS}

Audisio, I. Nietzsche y el papel de la "nouvelle psychologie" en la construcción de su filosofía. Revista de Humanidades, 26, p. 23-49, 2012.

Campioni, G. (Ed.). Nietzsche y el espíritu latino. Buenos Aires: El Cuenco de Plata, 2004.

Gampioni, G. \& Venturelli, I. (Ed.). La biblioteca ideale di Nietzsche. Napoli: Guida, 1992.

Casares, M. B. Introducción a Humano, demasiado humano. Madrid: Akal, 1996.

Colli, G. \& Montinari, M. (Ed.). Friedrich Nietzsche Sämtliche Werke. Kritische Studienausgabe. Berlin: Walter de Gruyter, 1994. 15v. (SW)

Gauchet, M. El inconsciente cerebral. Buenos Aires: Nueva Visión, 1994.

Gовтне, J. W. Teoría de la naturaleza. Madrid: Tecnos, 1997.

Lange, F. A. Geschichte des Materialismus und Kritik seiner Bedeutung in der Gegenwart. Iserlohn/Leipzig: Baedecker, 1866.

Müller, J. (Ed.).Archiv für Anatomie, Physiologie und wissenschaftliche Medicin. Berlin: Veit, 1838.

Müller-Lauter, W. L'organismo come lotta interna. L'inlusso di Wilhelm Roux su Friedrich Nietzsche. In: Campioni, G. \& Venturelli, S. (Ed.). La biblioteca ideale di Nietzsche. Napoli: Guida, 1992. p. $15^{3-}$ 200.

Nietzsche, F.W. Más allá del bien y del mal. Madrid: Alianza, 1983. .Humano, demasiado humano. Madrid: Akal, 1996. La genealogía de la moral. Madrid: Alianza, 2000.

Orsucgi, A. Dalla biologia cellulare alle scienze dello spirito. Aspetti del dibattito sull'individualità nell'Ottocento tedesco. Bologna: Il Mulino, 1992.

PfLÜGER, E. Die sensorischen Funktionen des Rückenmarks der Wirbeltiere nebst einer neuen Lehre über die Leitungsgesetze der Reflexionen. Berlin: Auguste Hirschwald, ${ }_{18} 5^{3 .}$

Rıвот, T. Les maladies de la volonté. Paris: Baillière, 1883.

Roux, W. Der Kampf der Theile im Organismus. Leipzig: Engelmann, 1881.

Sснаснт, R. O naturalismo de Nietzsche. Cadernos Nietzsche, 29, p. 35-75, 2011.

Schleiden, M. J. Beiträge zur Phytogenesis. In: Müller, J. (Ed.). Archiv für Anatomie, Physiologie und wissenschaftliche Medicin. Berlin: Veit, 1838. p. 137-76.

Schwann, T. Mikroskopische Untersuchungen über die Übereinstimmung in der Struktur und dem Wachsthum der Thiere und Pflanzen. Berlin: Reimer, 1839.

Taine, H. Voyage aux Pyrénées. Paris: Hachette, $185^{8}$. . De l'intelligence. Paris: Hachette, 1870.2 v.

Les éléments et la formation de l'idée du moi. Revue Philosophique de la France et de l'Étranger, 1, 1-6, p. $289-321,1876$.

. Nouveaux essais de critique et d'histoire. Paris: Hachette, 1909.

Les origines de la France contemporaine: L'Ancien Régime. Paris: Laffont, 1986.

Thiele, L. P. Friedrich Nietzsche and the politics of the soul. A study of the heroic individualism. Princeton: Princeton University Press, 1990.

Virchow, R. Die Cellularpathologie in ihrer Begründung auf physiologische und pathologische Gewebelehre. Berlin: Hirschwald, $185^{8}$. Vier Reden über Leben und Kranksein. Berlin: Reimer, 1862.

Vulpian, A. Leçons sur la physiologie générale et comparée du système nerveux faites au Muséum d'histoire naturelle. Paris: Baillière, 1866. 